\title{
美国对外农业投资格局演变及其影响因素 兼论“一带一路”农业合作
}

\author{
卢昱嘉, 陈秩分 \\ (中国农业科学院农业经济与发展研究所, 北京 100081)
}

\begin{abstract}
摘要：对外农业投资是“一带一路” 倡议的重要内容, 研究美国对外农业投资特征, 既可总结先 行之国的发展经验, 也可响应并适应主要竞争对手的投资行为, 为充分利用两个市场、两种资 源提供科学依据。本文立足对外直接投资理论, 采用Logistic 模型与面板数据分析方法, 研究 了2000-2018年美国对外农业投资的时空格局、影响因素及其对“一带一路”农业合作的启示。 结果表明: (1)美国对外农业投资以食品加工等产前产后环节为主, 主要分布于西欧等发达国 家以及墨西哥、巴西等地理临近的发展中国家。(2)美国对外农业投资呈现显著的市场导向特 征, 同时也受到地理与文化距离、国家治理等东道国因素的影响。(3)对比中美对外农业投资特 征, 结合当前国际经贸形势与中国农业国际合作目标, 建议中国进一步优化农业产业链布局, 在促进实现联合国可持续发展目标的同时, 提高中国在全球粮安领域的定价权与渠道把控力; 进一步深耕既有对外农业投资市场, 在降低地缘竞争压力的同时, 充分挖掘潜在市场机会; 关 注 “一带一路”沿线国家的农业技术需求, 保证投资目标与东道国的投资需求相协调; 尤需解决 中国对外农业投资面临的文化与体制差异较大等现实问题, 提高 “一带一路”农业合作项目的 可持续性。
\end{abstract}

关键词：对外农业投资;全球农业资源; 区位选择;“一带一路”倡议;美国

我国人多地少，人均耕地面积与淡水资源分别仅为全球平均水平的 $40 \%$ 与 $28 \%$ 。为 了保障日益增长的国内食物需求、降低不断紧张的资源环境压力, 客观上需要在稳定国 内农业生产的同时，充分利用好两个市场、两种资源 ${ }^{[1]}$ 。在此背景下，我国农产品进口规 模呈现持续增加趋势, 于 2004 年首次成为农产品净进口国, 且净进口规模呈现持续增加 趋势，其中，大豆、高粱、大麦等土地密集型农产品进口规模屡创新高。农产品贸易为 我国 “进口” 了大量的虚拟水与虚拟耕地资源 ${ }^{[1,2]}$, 同时也引发了进口依存度高、国内市 场冲击大等发展隐忧, 并在中美贸易战中得到了集中体现 ${ }^{[3]}$ 。相比而言，对外农业投资作 为一种主动的全球农业资源配置行为, 既可以针对全球尤其是发展中国家存在的农业资 金短缺问题，助推东道国农业发展，也可以生产和掌控更多的农产品，在促进全球食物 安全的同时保障国内粮食的稳定供应。因此，对外农业投资在提高中国农业对外合作话 语权与影响力中的作用日益显著, 成为“一带一路” 农业合作的重要手段 ${ }^{[4-6]}$ 。

数据显示，中国对外农业投资呈现蓬勃发展趋势，对外农业投资规模已于 2013 年首 次超过引进农业外资规模，涉足农业产前、产中、产后各个环节，以及东南亚、非洲、

收稿日期：2019-09-05；修订日期：2019-12-31

基金项目：国家自然科学基金项目（41871109); 中国农业科学院科技创新工程项目（ASTIP-IAED-2020-06）

作者简介: 卢昱嘉（1996- ), 女, 陕西渭南人, 硕士, 研究方向为农业经济管理。E-mail: 13259088787@163.com

通讯作者: 陈秧分 (1983-), 男, 湖南湘乡人, 博士, 研究员, 博士生导师, 研究方向为乡村产业经济、国际农业 经济。E-mail: chenyangfen@caas.cn 
南美洲等不同区域。这些对外投资取得了促进东道国农业发展、改善小农生计、增加粮 食产量等积极效果，同时也存在项目可持续性偏差、恶性竞争等诸多现实问题 ${ }^{[5,7,8]}$ 。对外 农业投资项目效果偏低，与中国是农业 “走出去” 的后起之国、缺少对外投资经验以及 健全的支持政策体系有着显著关联，也因中国对外农业投资影响全球的地缘政治格局， 遭到西方媒体诸如 “新殖民主义” “土地掠夺” 等扭曲性报道，进而损害中国对外农业投 资环境、影响对外农业投资项目运行 ${ }^{[5,9,10]}$ 。随着中国国力的不断上升、国内资源环境压力 的持续紧张以及 “一带一路” 倡议的深人推进，预计中国对外农业投资规模将继续快速 增长。如何优化中国的对外农业投资格局、促进农业对外投资的提质增效，是亟待研究 解决的现实问题。

对外农业投资属于外商直接投资的一种。已有研究围绕全球对外投资网络 ${ }^{[1]}$ 、国别 投资特征 ${ }^{[12]}$ 、典型行业格局 ${ }^{[13]}$ 、“一带一路” 合作 ${ }^{[14,15]}$ 等相关领域开展了深人分析。具体 到对外农业投资领域，多关注对外农业投资问题 ${ }^{[8]}$ 、对外农业投资战略 ${ }^{[9,16]}$ 、全球农业战 略 ${ }^{[17,18]}$ 、全球农业资源利用 ${ }^{[19]}$ 、海外耕地投资 ${ }^{[2,21]}$ 、农业 “走出去” 支持政策等对策途 径; 关于美国对外投资研究，主要关注投资区位选择 ${ }^{[2]}$ 、影响因素 ${ }^{[23]}$ 、投资经验 ${ }^{[24]}$ 等领 域，关注农业领域美国对外投资的研究较少，多从国际援助视角关注美国对发展中国家 的农业投资策略 ${ }^{[23]}$ 和投资效果 ${ }^{[2]}$ 。总体而言，全行业尤其是非农行业的对外直接投资研 究相对较为丰富, 农业领域的对外直接投资研究多为全球尺度、定性方法与对策分析。 本文选取美国作为研究对象，定量分析其对外农业投资格局及其影响因素。既可以借鉴 先行之国美国的发展经验，从地缘政治角度考量美国这一重要竞争对手的情况，为中国 深人推进农业领域的 “一带一路” 合作、提高农业对外投资项目的可持续性提供科学依 据，也可以结合农业项目的高度敏感性、长周期性与高风险性特征，尝试探索农业领域 对外投资的规律性特征，丰富和发展对外直接投资研究。

\section{1 研究方法与数据来源}

\section{1 理论分析}

对外农业投资属于国际直接投资行为。早在 1960s，海默即指出垄断优势是跨国企业 进行对外投资的主要动因，资金、技术、信息管理、规模经济等方面的市场不完全及其 衍生的企业特定优势，使得企业具备对外投资并获取超额利润的动机与能力。弗农从产 品生命周期的角度，指出直接投资由发达国家策源地向条件相近但又具有一定区位优势 的其他发达国家、广大发展中国家依次演化，籍此实现企业垄断优势与东道国区位优势 的有机结合，巩固和扩大市场占有率。由于原材料、半成品，尤其是技术、知识、管理 技能等中间产品市场存在缺陷，企业具有将外部市场内部化的客观动力，当市场内部化 行为跨越国界时，即产生了对外直接投资行为。在整合垄断优势、内部化理论与区位优 势的基础之上，邓宁创建了一个融合国际贸易、对外直接投资和国际协议安排的理论分 析框架，指出只有三种优势都具备时，企业才会选择对外直接投资。小岛清的边际产业 扩张理论则考虑了各国之间的比较优势，认为对外直接投资应从投资国已经处于或即将 处于比较劣势地位、东道国具有比较优势或潜在优势的产业（边际产业）开始，这样可 以更好地发挥双方比较优势, 取得双赢结果。除了以上主流的对外直接投资理论外, 波 特的竞争优势理论指出企业通过组织跨国生产来实现价值链增值，因激烈的国际竞争会 
产生对外投资并因此获取竞争优势（价值增值）；威尔斯的小规模技术理论认为发展中国 家拥有为小市场需求服务的小规模生产技术，“当地采购和特殊产品” 给发展中国家带来 竞争优势、低价产品营销战略等比较优势，也可以产生对外直接投资行为; 一些国际经 济学者提出投资诱发要素组合理论, 认为任何形式的对外直接投资, 都取决于投资直接 诱发要素与间接诱发要素的共同作用 ${ }^{[2]}$ 。由上可知，不同视角的对外直接投资原因存在 一定差异，但总体而言，对外直接投资仍根源于双方的比较优势（垄断优势、区位优 势、内部化理论)，瞄准资源、市场等核心诉求，在国际、国家、企业等不同尺度因素的 影响作用下, 通常由发展水平较高的国家向发展水平相仿或较低的国家转移, 藉此实现 价值增值、市场占有率最大化等特定企业动机。

\section{2 研究方法}

\subsection{1 变量选取}

根据现行统计标准，狭义的农业产业即为农林牧渔业，包括种植业、林业、畜牧业 与渔业等第一次产业, 广义的农业产业还包括食品加工、饮料与烟草、农产品批发、仓 储物流、农机制造、种子研发等涉农行业。2018年美国农林牧渔业对外投资规模为 65.26 亿美元，仅占当年对外投资总规模的 $0.1 \%$ ，同期食品加工业对外投资规模为 908.79 亿美 元，占 $1.5 \%$ 。考虑美国食品加工业投资占比较高、美国农林牧渔业投资对中国也具借鉴 意义、其他行业缺乏数据或难以剔除非农用途（如仓储物流设施不仅用于农食产品）等 因素，本文将具体分析农林牧渔业、食品加工业这两个行业的对外投资格局特征，以食 品加工业为例分析美国对外农业投资布局的影响因素。按照美国经济分析局（BEA）分 类，农林牧渔业包括作物种植、动物养殖、林业与伐木业、渔业与狩猎、支持农业和林 业的活动等具体投资产业, 食品加工业包括动物食品生产、谷物与油籽加工、糖与糖类 制品、果蔬保鲜及特色食品、乳制品、动物屠宰加工、海鲜产品制备与包装、烘培制 品、其他食品等产业。

根据理论分析，对外投资立足于双方的比较优势，受到国际、国家、企业等不同尺 度因素的影响，实现资源获取、生产率提高、市场扩张、技术进步等投资目的 ${ }^{[27]}$ 。以此 为基础，结合数据完整性和可获得性，从资源、市场、投资环境等方面来选取研究指标 (表1)。

从资源角度看，食品加工业的上游产业包括农、林、牧、渔等多种产业。由于农产 品生产的非标准性、易腐性等特点, 通常认为食品加工业属于典型的原料导向型布局产 业 ${ }^{[13]}$ 。东道国的农业资源、自然资源越丰裕，基础设施越完善，食品加工企业获得的原 材料及相应资源就越多，所消耗的成本就越小 ${ }^{[21]}$ ，理论上有利于投资国与东道国结合双 方的比较优势, 实现跨国的生产行为内部化, 实现双赢目标。选取人均耕地面积、自然 资源丰度、基础设施等变量来衡量东道国的农业资源禀赋。

从市场角度看, 食品加工业通常也直接面向消费者, 因此, 市场规模与市场潜力也 是决定企业能否持续稳定经营的重要指标。需要说明的是：(1) 一国的经济开放程度决 定了国内外市场消费的可能性，由于投资国的投资动机、类型、发展阶段不同，投资与 贸易可能相互促进，也可能表现出替代关系，但无论如何，越开放的经济就意味着更为 广阔的市场空间 ${ }^{[27]}$ ；(2) 经济自由度决定了企业在东道国的经营条件和国内市场发展空 间, 是影响长期投资决策的重要因素。因此, 选取总人口、经济发展水平、对外开放程 
表 1 变量选取与数据来源

Table 1 Variable selection and data source

\begin{tabular}{|c|c|c|c|}
\hline 分类 & 变量 & 指标解释 & 数据来源 \\
\hline \multirow[t]{3}{*}{ 资源因素 } & 人均耕地面积 $x_{1}$ & 耕地面积/人口总数 & 世界银行 \\
\hline & 自然资源丰度 $x_{2}$ & 自然资源租金总额占 GDP 比例 & 世界银行 \\
\hline & 基础设施 $x_{3}$ & 固定资产总额占 GDP 比例 & 世界银行 \\
\hline \multirow[t]{4}{*}{ 市场因素 } & 总人口 $x_{4}$ & 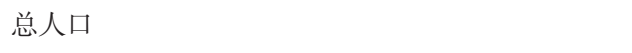 & 世界银行 \\
\hline & 经济发展水平 $x_{5}$ & 人均 GDP & 世界银行 \\
\hline & 对外开放程度 $x_{6}$ & 进出口总额占 GDP 比例 & 世界银行 ～～～～～～～～～～～ \\
\hline & 经济自由度 $x_{7}$ & 反映政府对经济的干涉水平 & 美国传统遗产基金会 \\
\hline \multirow{5}{*}{$\begin{array}{l}\text { 投资环境 } \\
\text { 因素 }\end{array}$} & 地理距离 $x_{8}$ & 首都间的经纬度距离 & CEPII数据库 \\
\hline & 共同官方语言 $x_{9}$ & 是否使用统一官方语言 & CEPII数据库 \\
\hline & 政治稳定性 $x_{10}$ & $\begin{array}{l}\text { 由各国恐怖主义、政治风险规模、安全风险评级、 } \\
\text { 内部和外部冲突强度、民族关系测定 }\end{array}$ & 全球治理指标(WGI)数据库 \\
\hline & 政府效率 $x_{11}$ & $\begin{array}{l}\text { 公众对公共服务质量、公务员的质量及其在政治压 } \\
\text { 力下的独立程度、政策制定和执行的质量以及政府 } \\
\text { 对此类政策承诺的可信度 }\end{array}$ & 全球治理指标(WGI)数据库 \\
\hline & 法治完善度 $x_{12}$ & $\begin{array}{l}\text { 由各国暴力犯罪、有组织犯罪、司法程序的公正 } \\
\text { 性、司法裁决的及时性、法院命令的执行程度、 } \\
\text { 知识产权保护、私有财产保护测定 }\end{array}$ & 全球治理指标(WGI)数据库 \\
\hline
\end{tabular}

度和经济自由度来代表东道国的市场因素，其中总人口和经济发展水平直接衡量东道国 的消费能力，对外开放程度衡量农产品贸易便利性及由此决定的国际市场空间，经济自 由度衡量企业发展空间及国内市场潜力。

从投资环境角度看，已有研究表明，投资国与东道国之间地理距离、政策制度、文

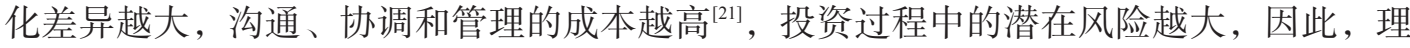
论上，企业会优先选择制度及环境相近的国家和地区进行投资。此外，政府的效率和政 治的稳定对投资国投资决策和外来企业经营条件都有重要影响 ${ }^{[28]}$ 。由此，选取地理距 离、共同官方语言、政治稳定性、政府效率、法治完善度等指标来反映东道国的投资环 境因素。

\section{2 .2 定量方法}

在分析美国对外农业投资格局特征的基础上，从是否吸引了美国对外农业投资、吸 引的美国农业投资规模两个方面，分别分析对外农业投资布局的影响因素。两种情况分 别对应无权投资格局（区位选择分析）与加权投资格局（规模选择分析），可以相互佐证 研究结论的稳健性。

\section{（1）区位选择分析}

对于无权投资格局，主要衡量是否吸引了美国对外农业投资。将美国对外投资作为 0-1 变量, 若当年美国对某国产生了农业投资, 记为 1 , 反之记为 0 , 藉此构建起美国农 业领域的无权对外投资网络。由于被解释变量为 0-1二值变量, 选择 Logistic 模型分析其 影响因素。Logistic 模型属于定性的个体选择模型, 用来估计决策者在若干备选方案中选 择其中一种的概率，美国投资发生的概率记为 $p$ ，即被解释变量的期望，未投资的概率 为 $1-p$, 引人 Logit 变换, 对发生比 $p /(1-p)$ 取对数, 即对数差异比, 再与自变量线性回 
归，分析提高这种概率的影响因素。参数估计采用极大似然估计，显著性检验采用似然 比检验，公式如下：

$$
\ln \left(\frac{p}{1-p}\right)=\beta_{0}+\beta_{i} x_{i}+\partial
$$

(2) 规模选择分析

引人美国对外农业投资规模，将无权投资网络中对外投资取 1 的国家作为研究对 象，构建起美国农业领域的加权对外投资网络，以各自的投资额为被解释变量分析美国 对外农业投资格局选择的影响因素。由于解释变量中包含不随时间改变的虚拟变量（地 理距离、共同官方语言)，面板数据模型中的固定效应模型不适用，因此选用随机效应模 型进行分析。记美国对外农业投资规模为 $y$ ，则模型公式为:

$$
\begin{gathered}
y_{i t}=\beta_{0}+\beta_{1} x_{1 i t}+\beta_{2} x_{2 i t}+\beta_{3} x_{3 i t}+\beta_{4} x_{4 i t}+\beta_{5} x_{5 i t}+\beta_{6} x_{6 i t}+\beta_{7} x_{7 i t}+\beta_{8} x_{8 i t}+ \\
\beta_{9} x_{9 i t}+\beta_{10} x_{10 i t}+\beta_{11} x_{11 i t}+\beta_{12} x_{12 i t}+\varepsilon_{i t}
\end{gathered}
$$

式中： $i$ 为国家; $t$ 为年份； $x_{1} \sim x_{12}$ 的定义见表 $1 ; \beta_{0} \sim \beta_{12}$ 为模型回归系数; $\partial 、 \varepsilon$ 为误 差项。

\section{3 数据来源}

以美国经济分析局（BEA）发布的《国际收支和直接投资头寸数据》为美国对外农 业投资的数据来源。美国对外农业投资包括农林牧渔业和食品加工业两个部分，考虑数 据可获得性以及农林牧渔业与食品加工业两者之间的悬殊比例，本文将同时用农林牧渔 业和食品加工业来分析美国对外农业投资格局，选取食品加工业来分析美国对外农业投 资格局的影响因素。在分析影响因素时，区位分析用于研究是否吸引了美国对外农业投 资，结合数据可获得性与延续性，最终包含了全球 198 个国家（地区）；规模分析用于研 究对外农业投资规模的决定因素，包含美国食品加工业对外投资涉及的 55 个东道国，各 影响因素的数据来源见表 1 。研究时段为 2000-2018 年, 既考虑到了这些数据的可获得 性，同时也考虑到与中国加人WTO 的时间节点基本吻合。极个别国家缺少极个别年份的 某个指标数据, 采取均值插补法进行处理, 总观察样本分别为 3762 个和 1045 个。

\section{2 结果分析}

\section{1 美国对外农业投资的格局特征}

\section{1 .1 美国对外农业投资规模总体呈现增加趋势}

2000 年以来，美国对外农业投资规模总体上呈现增加趋势。其中，农林牧渔业对外 投资规模由 2000 年的 17.52 亿美元增加为 2018 年的 65.26 亿美元，年均递增 $7.6 \%$ ；同期 食品加工业由 234.97 亿美元增加为 908.79 亿美元，年均递增 7.8\%（图 1）。这与美国农业 （食品加工）行业的强大竞争力有着显著关联，2018年全球十大食品企业中，亿滋、百 事、可口可乐、ADM、泰森食品、嘉吉等六所企业均来自美国，涵盖了饮料、休闲食 品、大宗农产品生产及综合加工、畜命养殖等多个行业, 推动了美国农业在全球的布局 扩张。美国的对外农业投资促进了东道国农业增长和收人增加，为美国农牧产品创造了 更广阔的新市场，实现了“双赢” ${ }^{[29]}$ 。

\section{1 .2 美国对外农业投资集中在产前产后环节}

美国对外农业投资相对集中于食品加工等产前产后环节，较少直接涉足农业生产环

节。以 2018 年为例，美国农林牧渔业对外投资与食品加工业对外投资的比例为 7.18: 


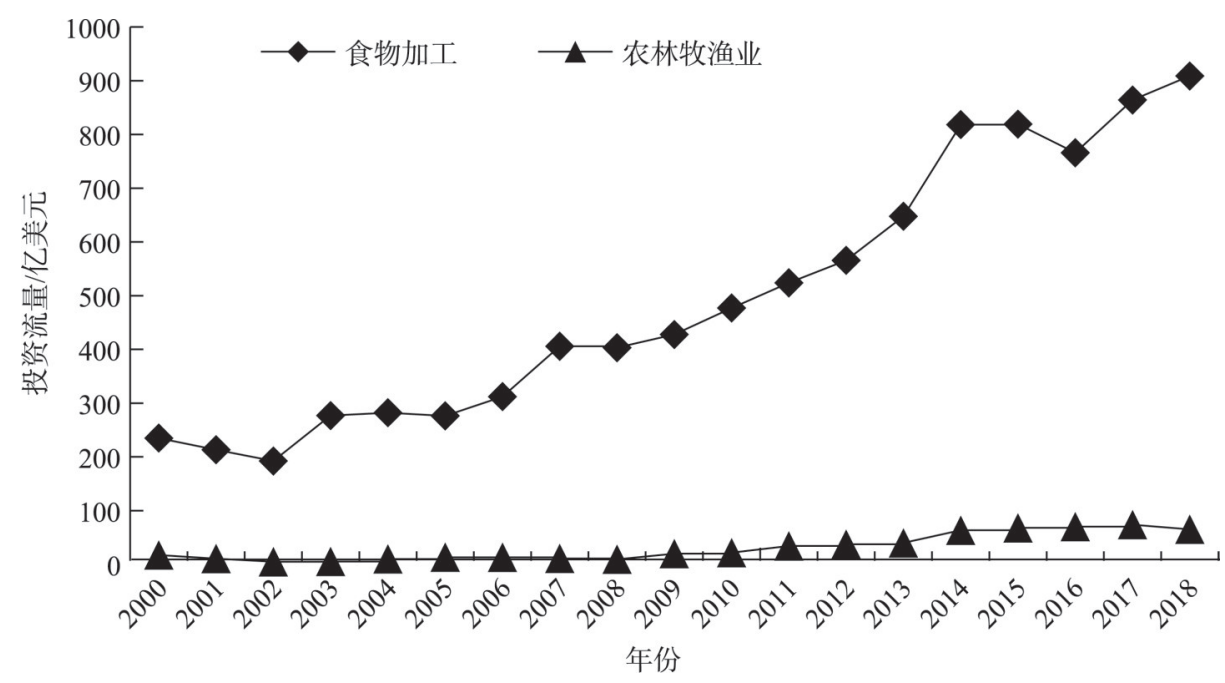

图 1 2000-2018年美国对外农业投资规模

Fig. 1 Scale of USA's overseas investment in agriculture from 2000 to 2018

100。具体来看, 在食品加工行业中, 果蔬保鲜及特色食品、谷物及油籽加工这两个产业 投资最多，占比分别为 $12.9 \%$ 和 $11.8 \%$ ；农林牧渔业对外投资中作物种植投资占比最大， 达到 57.0\%（表 2）。以全球四大粮商之一的美国嘉吉公司为例，其对外投资涉足粮油、 肉类等多个品类，侧重加工、仓储、物流等高附加值环节，近年来还加强了动物营养、 动物蛋白等细分领域的投资布局，逐步形成了覆盖全球、侧重流通、整合全产业链的发 展布局。

表 $22000-2018$ 年美国涉农产业对外投资的结构分布

Table 2 Structure of USA's overseas investment in agriculture from 2000 to 2018

\begin{tabular}{lccccc}
\hline & 2000 年 & 2005年 & 2010年 & 2015 年 & 2018 年 \\
\hline 食品加工业 & 234.97 & 276.38 & 477.04 & 819.14 & 908.79 \\
$\quad$ 动物食品生产 & 14.10 & 12.57 & 12.39 & - & 15.08 \\
谷物和油籽加工 & 46.21 & 54.03 & 79.61 & 97.72 & 106.98 \\
$\quad$ 糖和糖类产品 & 23.19 & 19.06 & 157.24 & - & - \\
果蔬保鲜及特色食品 & 35.20 & 22.00 & 45.79 & 115.64 & 117.53 \\
乳制品 & 4.52 & 8.91 & 24.45 & 58.43 & 37.62 \\
动物屠宰加工 & 15.95 & - & 19.61 & 11.64 & 12.72 \\
海鲜产品制备与包装 & 0.38 & - & 0.21 & 1.42 & 1.92 \\
烘培制品 & 13.00 & 13.87 & 13.86 & 111.19 & - \\
其他食品 & 82.43 & 138.20 & 123.88 & 233.75 & 317.41 \\
农林牧渔业 & 17.52 & 13.37 & 21.75 & 68.00 & 65.26 \\
$\quad$ 作物种植 & 8.69 & 7.78 & 6.74 & 37.34 & 37.23 \\
畜禽养殖 & 2.19 & 4.52 & 10.23 & 13.49 & 14.22 \\
林业与伐木业 & 2.95 & 0.61 & 2.49 & 14.04 & 12.26 \\
$\quad$ 渔业与狩猎 & - & 0.21 & 0.00 & 0.19 & 0.19 \\
支持农业和林业的活动 & - & 0.25 & 2.30 & 2.94 & 1.36 \\
\hline
\end{tabular}




\subsection{3 美国对外农业投资以欧洲及拉美国家为主}

从区域分布来看，美国食品加工领域的对外投资较为集中地分布在欧洲与中亚地区 $(57.2 \%)$ ，其次为东亚与太平洋地区 $(19.7 \%)$ 、拉美与加勒比地区 $(9.5 \%)$ 和北美（加 拿大，9.3\%)，撒哈拉以南非洲 $(1.7 \%)$ 、南亚 $(1.6 \%)$ 、中东与北非地区 $(1.0 \%)$ 的投 资占比较少（表 3)。从国别来看，2018年美国食品加工领域按对外投资规模排序的前十 个国家依次为英国（250.34 亿美元）、加拿大（84.38 亿美元）、澳大利亚（83.70 亿美 元）、法国（65.62亿美元）、荷兰（63.19亿美元）、墨西哥（45.78亿美元）、中国（31.65 亿美元）、巴西（20.59亿美元）、意大利（20.13亿美元）、比利时（17.86亿美元）。对比 而言，2000 年分别为英国（40.58 亿美元）、加拿大（34.31 亿美元）、荷兰（26.65 亿美 元）、巴西（16.86亿美元）、墨西哥（14.27亿美元）、澳大利亚（13.27亿美元）、阿根廷 （11.63 亿美元）、德国（9.86亿美元）、意大利（7.46亿美元）、法国（6.84亿美元）。由此 可知，美国对外农业投资较为集中地分布在经济发展水平高、贸易自由、外资政策宽松 的发达国家，尤其是西欧国家，以及地理临近、资源丰富的墨西哥和巴西等拉美国家 (表 4)。中国自 2001 年加人 WTO 以来日益成为美国重要的对外投资目标国，由 2000 年

表 $32000-2018$ 年美国食品加工领域的对外投资分布

Table 3 Distribution of USA's overseas investment in food processing industry from 2000 to 2018

\begin{tabular}{|c|c|c|c|c|c|c|c|c|c|c|}
\hline & \multicolumn{2}{|c|}{ 2000年 } & \multicolumn{2}{|c|}{2005 年 } & \multicolumn{2}{|c|}{ 2010年 } & \multicolumn{2}{|c|}{2015 年 } & \multicolumn{2}{|c|}{ 2018年 } \\
\hline & $\begin{array}{l}\text { 规模/ } \\
\text { 亿美元 }\end{array}$ & $\begin{array}{c}\text { 占比/ } \\
\%\end{array}$ & $\begin{array}{c}\text { 规模/ } \\
\text { 亿美元 }\end{array}$ & $\begin{array}{c}\text { 占比/ } \\
\%\end{array}$ & $\begin{array}{l}\text { 规模/ } \\
\text { 亿美元 }\end{array}$ & $\begin{array}{c}\text { 占比/ } \\
\%\end{array}$ & $\begin{array}{c}\text { 规模/ } \\
\text { 亿美元 }\end{array}$ & $\begin{array}{c}\text { 占比/ } \\
\%\end{array}$ & $\begin{array}{c}\text { 规模/ } \\
\text { 亿美元 }\end{array}$ & $\begin{array}{c}\text { 占比/ } \\
\%\end{array}$ \\
\hline 合计 & 234.97 & 100.0 & 276.38 & 100.0 & 477.04 & 100.0 & 819.14 & 100.0 & 908.79 & 100.0 \\
\hline 北美(加拿大) & 34.31 & 14.6 & 27.18 & 9.8 & 60.79 & 12.7 & 125.71 & 15.4 & 84.38 & 9.3 \\
\hline 撒哈拉以南非洲 & 2.13 & 0.9 & 1.65 & 0.6 & 3.61 & 0.8 & 12.59 & 1.5 & 14.96 & 1.7 \\
\hline 中东与北非 & 1.33 & 0.6 & 0.99 & 0.4 & 1.84 & 0.4 & 8.54 & 1.0 & 9.45 & 1.0 \\
\hline 拉美与加勒比 & 53.09 & 22.6 & 52.31 & 18.9 & 61.89 & 13.0 & 67.25 & 8.2 & 86.72 & 9.5 \\
\hline 欧洲与中亚 & 118.73 & 50.5 & 163.46 & 59.1 & 231.49 & 48.5 & 418.84 & 51.1 & 519.39 & 57.2 \\
\hline 东亚与太平洋 & 24.19 & 10.3 & 28.76 & 10.4 & 116.44 & 24.4 & 172.56 & 21.1 & 179.17 & 19.7 \\
\hline 南亚 & 0.84 & 0.4 & 0.39 & 0.1 & 0.94 & 0.2 & 10.07 & 1.2 & 14.72 & 1.6 \\
\hline 中国 & 2.86 & 1.2 & 4.02 & 1.5 & 43.39 & 9.1 & 39.36 & 4.8 & 31.65 & 3.5 \\
\hline
\end{tabular}

注：地区分类参照世界银行的分类标准。

表 4 美国食品加工业对外投资主要目标国特征

Table 4 Characteristics of the main target countries of the USA's overseas investment in food processing industry (亿美元)

\begin{tabular}{llcl}
\hline 国家 & 所在地区 & 投资规模 & 主要特征 \\
\hline 英国 & 欧洲与中亚 & 250.34 & 经济发达、政治稳定、体制相近、语言一致等 \\
加拿大 & 北美 & 84.38 & 经济发达、政治稳定、体制相近、语言一致、地理临近、资源丰富等 \\
澳大利亚 & 东亚与太平洋 & 83.70 & 经济发达、政治稳定、体制相近、语言一致、资源丰富等 \\
法国 & 欧洲与中亚 & 65.62 & 经济发达、政治稳定、体制相近、农业发达、资源丰富等 \\
荷兰 & 欧洲与中亚 & 63.19 & 经济发达、政治稳定、体制相近、农业发达等 \\
墨西哥 & 拉美与加勒比 & 45.78 & 地理临近、自由贸易区等 \\
巴西 & 拉美与加勒比 & 20.59 & 地理临近、资源丰富、贸易自由等 \\
意大利 & 欧洲与中亚 & 20.13 & 经济发达、政治稳定、体制相近、农业发达等 \\
\hline
\end{tabular}

注：主要目标国仅指美国食品加工业对外投资规模在 2000年、2018年均位于前十名的国家。 
的 2.86 亿美元（占 $1.2 \%$ ）锐增至 2011 年的 45.23 亿美元（占 $8.6 \%$ ）, 但近几年呈现缓慢 下降趋势，2018年美国食品领域对华投资规模仅为 31.65 亿美元，占 3.5\%（表3）。

\section{2 美国对外农业投资的影响因素}

\subsection{1 美国对外农业投资呈现显著的市场导向特征}

从实证分析结果来看 (表 5$)$, 以总人口 $\left(x_{4}\right)$ 、人均 GDP $\left(x_{5}\right)$ 衡量的市场消费 能力在两个模型中均显著为正, 用经济自由度 $\left(x_{7}\right)$ 衡量的国内市场空间在 Logistic 模 型中显著为正、在随机效应模型中正相关但不显著，表明美国对外农业投资或者说食品 加工领域的对外投资呈现明显的市场导向特征，侧重消费能力强、市场成熟的欧美以及 日韩等发达国家市场。值得注意的是，近年来，美国对发展中国家的农业投资也在不断 扩大。许多美国农业综合企业及农产品出口商认为, 发展中国家普遍具有人口众多且增 速较快、经济增长率高、高质量高价格食品需求不断增长等特点, 是开拓市场的最佳机 会 ${ }^{[26]}$ 。美国对外农业投资刺激发展中国家需求增长，扩大了美国农产品出口，创造了就 业机会, 东道国为美国消费者提供可靠、营养和安全的热带食品以及错季水果和蔬菜, 消费者也从中受益 ${ }^{[26]}$ 。相比而言, 资源因素的影响作用较弱, 三个解释变量中, 仅有人 均耕地 $\left(x_{1}\right)$ 这个指标在其中一个模型中正相关, 反映矿产、林业等广义资源禀赋的自 然资源（ $\left.x_{2}\right)$ 以及间接反映资源流通成本的基础设施（ $\left.x_{3}\right)$ 指标均不显著甚至为负。

\section{表 5 实证分析结果}

Table 5 Empirical analysis results

\begin{tabular}{|c|c|c|c|c|c|}
\hline \multirow{2}{*}{ 变量类型 } & \multirow{2}{*}{ 解释变量 } & \multicolumn{2}{|c|}{ Logistic 模型(投资区位) } & \multicolumn{2}{|c|}{ 随机效应模型(投资规模) } \\
\hline & & coef. & $z$ & coef. & $z$ \\
\hline \multirow[t]{3}{*}{ 资源因素 } & 人均耕地 $x_{1}$ & $2.683^{*}$ & 1.69 & 453.340 & 0.72 \\
\hline & 自然资源 $x_{2}$ & -0.038 & -1.47 & -15.471 & -1.04 \\
\hline & 基础设施 $x_{3}$ & 0.011 & 0.18 & 9.647 & 0.68 \\
\hline \multirow[t]{4}{*}{ 市场因素 } & 总人口 $x_{4}$ & $2.23 \mathrm{e}-06^{* * *}$ & 6.6 & $1.85 \mathrm{e}-06^{* *}$ & 2.37 \\
\hline & 人均 GDP $x_{5}$ & $4.88 \mathrm{e}-05^{* *}$ & 2.42 & $0.020^{* * *}$ & 4.16 \\
\hline & 对外开放度 $x_{6}$ & 0.001 & 0.06 & -0.376 & -0.16 \\
\hline & 经济自由度 $x_{7}$ & $0.121^{* * *}$ & 3.53 & 7.233 & 0.54 \\
\hline \multirow[t]{6}{*}{ 投资环境因素 } & 地理距离 $x_{8}$ & $-0.001^{* * *}$ & -2.93 & -0.070 & -1.1 \\
\hline & 共同官方语言 $x_{9}$ & -0.843 & -0.72 & $1179.682^{* *}$ & 1.64 \\
\hline & 政治稳定性 $x_{10}$ & 0.228 & 0.27 & -100.423 & -0.58 \\
\hline & 政府效率 $x_{11}$ & $2.468^{* *}$ & 2.01 & $-727.796^{* * *}$ & -2.56 \\
\hline & 法治完善度 $x_{12}$ & -0.389 & -0.33 & $590.963^{* *}$ & 2.00 \\
\hline & 常数 & $-10.261^{* * * *}$ & -5.77 & 180.881 & 0.18 \\
\hline
\end{tabular}

注: ***、***分别表示指标在 $10 \% 、 5 \% 、 1 \%$ 的显著性水平下统计结果显著。

\section{2 .2 美国对外农业投资受到地理与文化距离的影响}

地理距离 $\left(x_{8}\right)$ 在 Logistic 模型中显著负相关、在随机效应模型中负相关但不显 著，通过模型分析可以进一步证实美国对外农业投资更倾向于地理临近的周边国家，从 而起到降低风险、节约成本的作用。相应地, 共同官方语言 $\left(x_{9}\right)$ 在随机效应模型中显 著为正，在 Logistic 模型中虽为负但不显著，表明以共同官方语言为代表的文化距离会影 响企业的对外农业投资布局。这是因为，语言相通有利于跨国企业更好地利用东道国的 
技术、经验、知识等，累积学习效应，对海外投资规模扩大有正向促进作用；以语言相 通为代表的文化距离越短，则意味着市场进人与交易成本越低，企业进人积极性就越 高，在跨国合作中不易出现经济、社会问题，投资成功率更有保障；美国对外投资在农 业研发领域一般能带来较高的回报率 ${ }^{[26]}$ ，语言相通往往会拉动农业研发投资，有利于新 技术在东道国和美国推广和应用。某种程度上，一国对外投资相对集中的地区，同时也 是该国的传统势力范围或文化距离相对较短的地区，比如，俄罗斯的前苏联地区、英国 的英联邦地区、法国的北非地区，这对美国同样适用。

\section{2 .3 美国对外农业投资与东道国投资环境显著相关}

除地理距离、文化距离等相对客观的因素外，美国对外农业投资还受到东道国投资 环境尤其是法治完善程度（ $\left.x_{12}\right)$ 的影响。该变量在随机效应模型中显著为正，在Logistic 模型中为负但不显著，表明法治完善程度是影响美国对外农业投资非常重要的因素， 稳固的法律环境有助于优化东道国投资环境，同时也有助于保护外商直接投资，保障较 为稳定的市场预期。相较而言, 政治稳定性 $\left(x_{10}\right)$ 、政府效率 $\left(x_{11}\right)$ 的影响或不显著, 或两个模型的预估结果刚好相反，原因可能在于，美国对外农业投资既投向了政局稳 定、政府效率相对较高的东道国，也部分投向了政权更迭相对频繁、政府效率较低的东 道国，比如对撒哈拉以南非洲和南亚的农业投资比例明显上升。一方面非洲与美国农业 有较强互补性，投资非洲的经济增长符合美国的利益；另一方面美国以农业国际援助为 出发点，通过投资非洲的农业粮食系统，在满足其快速增长的粮食需求的同时，构建起 可持续、高效的全球粮食系统，从而使自身受益 ${ }^{[25]}$ 。

\section{3 中国“一带一路”农业合作启示}

\subsection{1 中国“一带一路”农业合作特征}

从行业分布来看，近年来，中国农业对外开放步伐不断加快，对外农业投资规模、 领域逐渐扩大，投资主体、方式日趋多元，在统筹利用两个市场、两种资源、两类规则 方面成效显著 ${ }^{[24]}$ 。2017 年中国对外直接投资 1582.9 亿美元，同比下降 $19.3 \%$ ，流量规模 仅次于美国（3422.7亿美元）和日本（1604.5 亿美元），位居世界第三位，其中对外直接 投资流向农林牧渔业 25.1 亿美元，占比 $1.6 \%$ ，较 2005 年的 $0.9 \%$ 上涨了 $84.4 \%$ （图 2)。

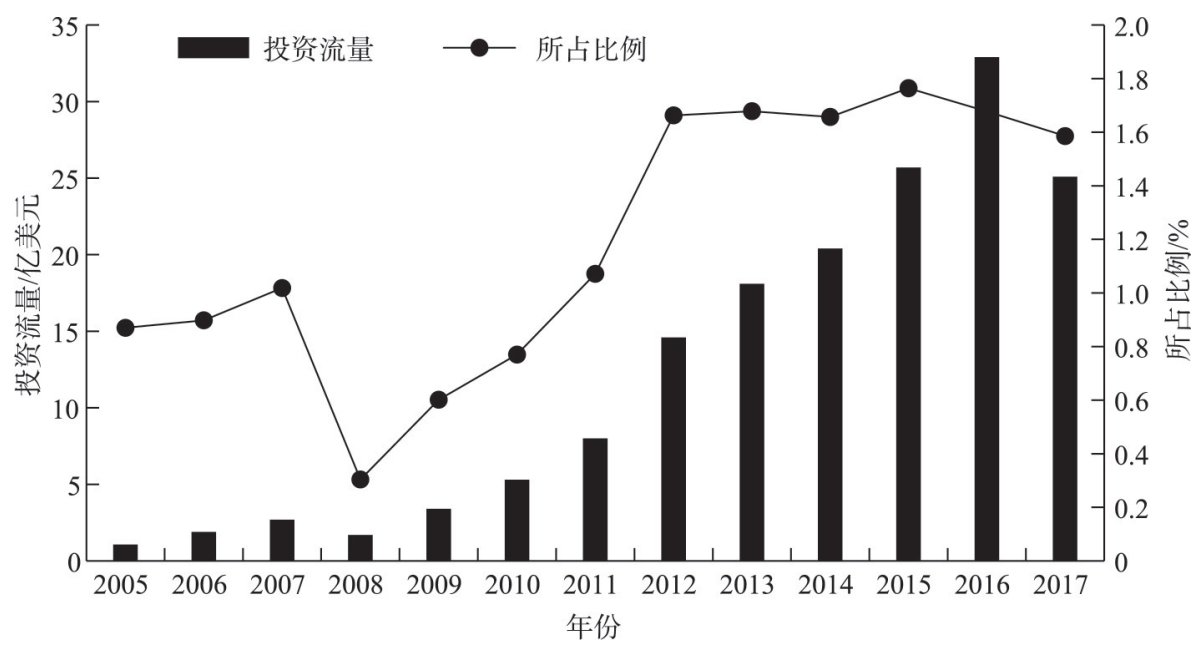

图 2 2005-2017年中国农林牧渔业对外投资规模

Fig. 2 Scale of China's overseas investment in agriculture from 2005 to 2017 
2017 年末中国农林牧渔业对外直接投资存量 165.6 亿美元，占 $0.9 \%$, 其中农业占 $27.8 \%$, 林业占 $16.6 \%$ ，渔业占 $11.1 \%$ 。农副食品加工业对外投资 2.7 亿美元，占比仅 $0.2 \%$ 。相 较而言, 中国对外农业投资较多地涉足农业生产环节, 较少涉及包括食品加工在内的产 前产后环节 ${ }^{[5,7,8]}$ ，这与美国侧重食品加工领域、较少涉及具体生产环节形成鲜明对比。

从区域分布来看，中国企业“走出去”进行农业开发集中在耕地资源较为丰富的国 家和地区 ${ }^{[8]}$, 投资动机包括土地便宜、市场机会和原料供应充足等 ${ }^{[9]}$, 主要以东南亚、中 亚和欧美发达国家、俄罗斯远东地区为目的地。这些国家拥有未开发的土地，往往愿意 接受中国的投资，寻求奶制品、牛肉和羊肉进口来源的中国企业把投资重点放在了新西 兰和澳大利亚。2017年，我国对亚洲农业投资 9.5 亿美元，对欧洲投资 7.1 亿美元，共占 我国农业对外投资流量的 $73.7 \%$ 。亚洲的主要投资国家包括老挝、泰国、柬埔寨、新加 坡、印度尼西亚等东盟国家，流向俄罗斯的农业投资占整个欧洲总量的一半以上 ${ }^{[30]}$ 。与 美国相比，我国对外农业投资同样受到地理和文化因素的影响，呈现相对一致的特征。

\section{3 .2 美国对外农业投资的启示}

美国是对外农业投资的先行之国，同时也是中国对外投资必须考虑的主要竞争对 手。结合美国对外农业投资格局及其影响因素，立足中国农业国际合作目标与当前国际 经贸形势，对中国“一带一路”农业合作可形成如下启示：

第一，优化农业产业链布局。美国主要投资于食品加工业而非农林牧渔业，但从全 球尤其是发展中国家的实际情况来看，粮食供应不足、内部资金缺乏导致农业生产停滞 仍是阻碍当地发展的主要瓶颈，是实现联合国可持续发展目标的优先任务 ${ }^{[16]}$ 。中国作为 负责任的大国，通过提供产前技术服务（种子、化肥、种植技术等）以及一定的资金支 持，提高亚洲、非洲、拉丁美洲等广大发展中国家的农业综合生产能力，同时加大产后 环节（仓储物流、精深加工等）的投资力度，以提高全球农产品的定价权与渠道把控 力，有效利用两个市场、两种资源。在整个过程中，既可利用好美国农业对外投资较少 涉足这些国家、当地食品加工与流通体系尚不健全的潜在机会, 也可促进中国对外农业 投资在当地的全产业链发展，切实提高对外农业投资项目效果。

第二，深耕现有对外农业投资市场。美国对外农业投资较为集中地分布在发达国家 尤其是西欧国家，以及地理临近的墨西哥、巴西等拉美国家，对非洲、东南亚地区发展 中国家的农业投资份额较少，但比例不断扩大，中国对外农业投资则主要分布在东南 亚、中亚、中东欧等地区。中国宜进一步深耕既有市场, 这既符合地理距离决定规律, 也可与美国形成错位发展, 减少地缘竞争压力。由于当地政治、自然风险较高, 中美农 业投资流向非洲、拉美市场都相对较少。2017年我国对非洲投资仅 1.5 亿美元，但投资 潜力较大 ${ }^{[24]}$ ，未来可考虑加大对非洲、拉丁美洲的合作力度，扩大既有投资目的地，重 点关注非洲公共农业研发和推广系统，克服其研发投人落后的薄弱环节，与美国形成合 理竞争。同时，也可以适当加大美国竞争产业的投资，比如新西兰乳制品、澳大利亚牛 肉、乌克兰玉米等，减少对美国农产品的进口依赖 ${ }^{[31]}$ 。

第三，关注 “一带一路”沿线国家的农业技术需求。美国对发展中国家的农业对外 投资以国际援助为出发点，在农业研发领域取得较高的回报率，刺激了东道国农业技术 需求，扩大了美国出口市场，也增加了美国无法生产的食品供应，使消费者受益。中国 对外农业投资主要面向研发投人较少、农业技术落后的发展中国家。从美国的农业援助 
投资经验来看，对外农业投资应在技术转让、创造就业、上下游联系等方面给东道国带 来发展利益 ${ }^{[32]}$, 需要重视农业研发领域, 考虑当地农业技术缺口和政策环境, 保证投资 目标与东道国的投资需要相协调，促进资本、机会等与实际需求相匹配。

第四，提高 “一带一路” 农业合作项目的可持续性。美国对外农业投资主要集中于 治理体系相对完善、文化与体制机制相对接近的发达国家，以食品加工业为主。相比而 言，中国对外农业投资主要集中于政治稳定性与法治完善度相对较弱、文化与体制机制 相对较远的发展中国家, 以农业生产环节为主, 风险与挑战相对较高。由此, 在推动 “一带一路” 农业国际合作的过程中, 需要更加重视双边及多边协议的加持, 需要实现双 方发展目标的战略耦合，需要更为尽职尽责的可行性论证，需要更强的信息与保险支 持，才可更好地化解各类风险与挑战，提高项目的可持续性。

\section{3 结论与讨论}

（1）美国是对外农业投资的先行之国，同时也是全球地缘竞争的主导力量。2000年 以来美国对外农业投资总体上呈现持续增加趋势，以食品加工等产前产后环节为主，农 业生产环节相对较少。投资区域主要为发达国家尤其是西欧国家，以及地理临近的墨西 哥、巴西等拉美国家，对非洲、南亚地区发展中国家的农业投资份额相对较少，但占比 不断扩大，其中对中国的农业投资以 2011 年为节点呈现先增加后减少的趋势。这些投资 呈现显著的市场导向特征，同时也受到地理与文化距离、国家治理等东道国因素的影 响，总体上投向地理邻近、经济水平较高、市场规模较大、政府管制宽松、法律制度完 善的发达地区。

（2）相比而言，中国对外农业投资集中于东南亚、中东欧等区域，以农业生产环节 为主, 呈现一定的资源导向型特征, 且由于起步较晚，尚欠缺较为健全的支持政策体 系。考虑当前国际经贸形势以及中国农业国际合作目标，建议中国进一步统筹农业产业 链布局，深耕现有对外农业投资市场，关注 “一带一路” 沿线国家的农业技术需求，切 实提高 “一带一路” 农业合作项目的可持续性，这样可以更好地借鉴美国的投资经验， 响应并适应美国的投资行为。

（3）总体而言，无论是美国对外农业投资，还是中国对外农业投资，都基本符合对 外直接投资的一般规律，例如，由发展水平相对较高的国家向发展水平相近或较低的国 家转移, 受到市场、资源等因素的影响。相较而言, 针对农业项目的高度敏感性、长周 期性与高风险性特征，美国的对外农业投资更好地体现了 “在商言商”，瞄准了价值增 值、市场占有率最大化等可持续目标；中国的对外农业投资，则因嵌人了 “道义责任” “后来者” 等外在因素，一定程度上呈现出与非农产业对外直接投资不一样的规律，例 如，投向政治稳定性与法治完善度相对较弱、文化与体制机制相对较远的发展中国家。

（4）本文从东道国的资源因素、经济因素、投资环境因素等方面切人，分析了美国 对外农业投资特征及其影响因素，可为优化我国对外农业投资布局、促进对外农业投资 提质增效提供一定的经验参考。受限于数据可获得性，在分析格局特征时，未纳人种子 研发、仓储物流、港口码头等重要环节; 在分析影响因素时, 行业上未考虑农林牧渔业 情况, 变量上未穷尽人力资本等影响变量, 但考虑到美国农林牧渔业投资占比非常小等 实际情况，以上分析应该能够揭示美国对外农业投资的基本规律。此外，“一带一路”合 
作启示主要基于中美对比，这些启示如何落实到国家与企业层面、如何做到 “在商言 商” 实现项目可持续、各国投资环境评价等等问题，还有待进一步深化研究。对美国具 体企业案例分析、美国支持政策监测等国别研究值得后续尝试。

\section{参考文献(References):}

[1] 刘爱民, 薛莉, 成升鬼, 等. 我国大宗农产品贸易格局及对外依存度研究: 基于虚拟耕地资源的分析和评价. 自然资 源学报, 2017, 32(6): 915-926. [LIU A M, XUE L, CHENG S K, et al. A study on the trade and external dependence of agricultural products in China: Analysis and evaluation based on virtual land resources. Journal of Natural Resources, 2017, 32(6): 915-926.]

[2] TAHERZADEH O, CARO D. Drivers of water and land use embodied in international soybean trade. Journal of Cleaner Production, 2019, 223(6): 83-93.

[3] 杜娟. 中美贸易争端对中国农业的影响及启示. 西北农林科技大学学报: 社会科学版, 2019, 19(3): 152-160. [DU J. The impacts and enlightenments on China's agriculture from the Sino-US trade war. Journal of Northwest A\&F University: Social Science Edition, 2019, 19(3): 152-160.]

[4] JIANG X Y, CHEN Y F, WANG L J. Can China's agricultural FDI in developing countries achieve a Win-Win Goal: Enlightenment from the literature. Sustainability, 2019, 11(1): 41-63.

[5] CHEN Y F, LI X D, WANG L J, et al. Is China different from other investors in global land acquisition? Some observations from existing deals in China's Going Global Strategy. Land Use Policy, 2017, 60(1): 362-372.

[6] ZHAN S H, ZHANG H Z, HE D Y. China's flexible overseas food strategy: Food trade and agricultural investment between Southeast Asia and China in 1990-2015. Globalizations, 2018, 15(5): 702-721.

[7] 赵立军, 陈秧分, 李先德. 基于粮食安全视角的海外农业投资关注与政策启示. 中国农业资源与区划, 2017, 38(1): 711, 30. [ZHAO L J, CHEN Y F, LI X D. Global concern and policy implication on overseas agricultural investment based in the perspective of food security. Chinese Journal of Agricultural Resources and Regional Planning, 2017, 38(1): 7-11,30.]

[8] 仇焕广, 陈瑞剑, 廖绍攀, 等. 中国农业企业“走出去”的现状、问题与对策. 农业经济问题, 2013, 34(11): 44-50, 111. [QIU H G, CHEN R J, LIAO S P, et al. Foreign agricultural investments of China's agricultural companies: Current status, difficulties, and policy suggestions. Issues in Agricultural Economy, 2013, 34(11): 44-50, 111.]

[9] 宋洪远, 张红奎. 我国企业对外农业投资的特征、障碍和对策. 农业经济问题, 2014, 35(9): 4-10, 110. [SONG H Y, ZHANG H K. Investment for agriculture in foreign countries by Chinese firms: Characteristics, barrier and choice of government. Issues in Agricultural Economy, 2014, 35(9): 4-10, 110.]

[10] 刘乃郗, 韩一军, 刘邦凡. 逆全球化背景下中国农业海外投资风险与对策. 哈尔滨工业大学学报: 社会科学版, 2018, 20(1): 127-132. [LIU N X, HAN Y J, LIU B F. Risks and countermeasures of China's agricultural overseas investment under reverse globalization. Social Sciences of Journal of Harbin Institute of Technology, 2018, 20(1): 127-132.]

[11] 杨文龙, 杜德斌, 游小珺, 等. 世界跨国投资网络结构演化及复杂性研究. 地理科学, 2017, 37(9): 1300-1309. [YANG W L, DU D B, YOU X J, et al. Network structure evolution and spatial complexity of global transnational investment. Scientia Geographica Sinica, 2017, 37(9): 1300-1309.]

[12] 黎明, 夏昕鸣, 朱晟君, 等. 中国对非直接投资时空演化及其影响因素. 经济地理, 2017, 37(11): 19-27. [LI M, XIA X M, ZHU S J, et al. Spatio-temporal evolution of China's OFDI in Africa countries and its influencing factor. Economic Geography, 2017, 37(11): 19-27.]

[13] 金少胜, 德永澄宪. 市场潜能、原材料接近度与日本食品产业在华投资的区位选择. 经济地理, 2010, 30(6): 976981. [JIN S S, TOKUNAGA S. Market potential, supplier access and location choices of Japanese food manufacturers in China. Economic Geography, 2010, 30(6): 976-981.]

[14] 刘卫东, MICHAEL D, 高菠阳. “一带一路”倡议的理论建构: 从新自由主义全球化到包容性全球化. 地理科学进 展, 2017, 36(11): 1321-1331. [LIU W D, MICHAEL D, GAO B Y. Discursive construction of the Belt and Road Initiative: From neoliberal to inclusive globalization. Progress in Geography, 2017, 36(11): 1321-1331.]

[15] 贾琨, 杨艳昭,封志明. “一带一路”沿线国家粮食生产的时空格局分析. 自然资源学报, 2019, 34(6): 1135-1145. [JIA K, YANG Y Z, FENG Z M. An evaluation of the Belt and Road cereals production from a view of spatial-temporal patterns. Journal of Natural Resources, 2019, 34(6): 1135-1145.]

[16] 陈秧分, 李先德, 王士海, 等. 农业和粮食系统负责任投资原则的影响研究. 农业经济问题, 2015, 36(8): 35-41, 110111. [CHEN Y F, LI X D, WANG S H, et al. Principles for responsible investment in agriculture and food systems: Im- 
pacts and countermeasures. Issues in Agricultural Economy, 2015, 36(8): 35-41, 110-111.]

[17] 程国强, 朱满德. 中国农业实施全球战略的路径选择与政策框架. 改革, 2014, 27(1): 109-123. [CHENG G Q, ZHU M D. The path-choosing and policy framework of agriculture implementing global strategy in China. Reform, 2014,27 (1): 109-123.]

[18] 李富佳, 董锁成, 原琳娜, 等. “一带一路”农业战略格局及对策. 中国科学院院刊, 2016, 31(6): 678-688. [LI F J, DONG S C, YUAN L N, et al. Study on agriculture patterns and strategy of the Belt and Road. Bulletin of Chinese Academy of Sciences, 2016, 31(6): 678-688.]

[19] 贾盼娜, 刘爱民, 成升鬼, 等. 中国农产品贸易格局变化及海外农业资源利用对策. 自然资源学报, 2019, 34(7): 1357-1364. [JIA P N, LIU A M, CHENG S K, et al. Pattern changes of China's agricultural trade and countermeasures for the utilization of overseas agricultural resources. Journal of Natural Resources, 2019, 34(7): 1357-1364.]

[20] 韩璟, 杨莼, 柯楠, 等. 中美对非洲海外耕地投资东道国的选择差异与影响因素分析. 中国土地科学, 2018, 32(8): 37-43. [HAN J, YANG C, KE N, et al. Analysis of the spatial difference and impact factors of China and America's overseas farmland investment host country selections in Africa. China Land Science, 2018, 32(8): 37-43.]

[21] 姜小鱼, 陈秧分, 王丽娟. 中国海外耕地投资的区位特征及其影响因素: 基于 2000-2016年土地矩阵网络数据. 中国 农业资源与区划, 2018, 39(9): 46-53. [JIANG X Y, CHEN Y F, WANG L J. The location characteristics and influencing factors of China's overseas arable land investment: Based on the 2000-2016 land matrix network data. Chinese Journal of Agricultural Resources and Regional Planning, 2018, 39(9): 46-53.]

[22] 罗长远, 毛成学, 柴晴圆. 美国对外直接投资: 中国是一个特别的目的地吗?. 金融研究, 2018, 61(12): 72-90. [LUO C Y, MAO C X, CHAI Q Y. US outward FDI: Is China a special host country?. Financial Research, 2018, 61(12): 7290.]

[23] 高丽峰, 李文芳, 于雅倩. 美国对外直接投资与产业升级的关系研究. 经济经纬, 2013, 30(6): 72-76. [GAO L F, LI W F, YU Y Q. Research on the relation between ODI and industrial upgrading in the United States. Economic Survey, 2013, 30(6): 72-76.]

[24] 郭周明. 美日对外投资分析及其对中国启示: 基于“一带一路”视角. 国际贸易, 2017, 36(6): 42-47. [GUO Z M. The analysis of US and Japan foreign investment and its enlightenment to China: Based on the perspective of "The Belt And One Road Initiative". International Trade, 2017, 36(6): 42-47.]

[25] THOMAS J, CHANCE K, ISAAC M. Enhancing United States efforts to develop sustainable agri-food systems in Africa. Farm Journal Foundation, 2017-02-01. http://www.agweb.com/assets/1/6/enhancingusefforts_print.pdf, 2017-02-01.

[26] Board for International Food and Agricultural Development, International Food Policy Research Institute, Association of Public and Land-Grant Universities. How the United States benefits from agricultural and food security investments in developing countries. Washington D C: International Food Policy Research Institute, 2019. https://oi.org/10.2499/ p15738coll2.133419, 2019-10-15.

[27] 萨尔瓦多. 国际经济学. 北京: 清华大学出版社, 2008. [SALVATIRE D. International Economics. Beijing: Tsinghua university Press, 2008.]

[28] 黄太宏, 周海望. 丝绸之路经济带视野下中国对中亚五国直接投资的动因研究. 经济问题探索, 2018, 39(3): 96107. [HUANG T H, ZHOU H Y. Research on the motivation of China's direct investment in the five central asian countries from the perspective of the Silk Road Economic Belt. Inquiry into Economic Issues, 2018, 39(3): 96-107.]

[29] MEGAN N. Benefits of investing in global agricultural R\&D spill over to U.S. farmers. American Farm Bureau Federation: Market Intel, 2019-07-23. http://www.fb.org/market-intel/benefits-of-investing-in-global-agriculture-rd-spill-overto-u.s.-farmers, 2019-07-23.

[30] 商务部, 国家统计局, 国家外汇管理局. 中国对外直接投资统计公报. 北京: 中国统计出版社, 2018. [Ministry of Commerce, National Bureau of Statistics, State Administration of Foreign Exchange. Statistical Bulletin of China's Outward Foreign Direct Investment. Beijing: China Statistics Press, 2018.]

[31] U.S. Department of Agriculture. China's foreign agriculture investments. Washington D C: Economic Research Service, 2018. http://www.ers.usda.gov/webdocs/publications/88572/eib-192.pdf, 2018-04-24.

[32] HALLAM D. International investment in developing country agriculture: Issues and challenges. Food Security, 2011, 3 (1): 91-98. 


\title{
Evolution pattern of USA's overseas investment in agriculture and its influencing factors:
}

\section{Concurrent discussion on agricultural cooperation in the Belt and Road region}

\author{
LU Yu-jia, CHEN Yang-fen \\ (Institute of Agricultural Economy and Development, Chinese Academy of Agricultural \\ Sciences, Beijing 100081, China)
}

\begin{abstract}
Overseas investment in agriculture is an important part of the Belt and Road Initiative (BRI). The research on the characteristics of USA's overseas investment in agriculture can provide scientific basis for a better use of domestic and international markets and resources, not only for drawing on USA's development experience, but also for responding and adapting to the investment behavior of major competitors. Based on the Outward Foreign Direct Investment theory, this paper adopts the logistic model and panel data analysis method to study the spatiotemporal pattern and influencing factors of USA's overseas investment in agriculture from 2000 to 2018, and discusses its policy implications for China's agricultural cooperation. The results show that: firstly, the USA's overseas investment in agriculture is mainly distributed on food processing and other pre- and post-production processes, mainly concerning developed countries such as Western European countries, as well as some neighbor developing countries such as Mexico and Brazil. Secondly, USA's overseas investment in agriculture showed a significant market orientation. In the meantime, it is also affected by geographical and cultural distance, national governance and other factors of the host country. Thirdly, in comparison of differences between China and the USA in characteristics of overseas investment in agriculture, considering the goal of China's international agricultural cooperation under the background of current international economic and trade situation, we suggested that China should further optimize the layout of agricultural industry chain, which will advance the implementation of sustainable development goals set by the United Nations and increase China's pricing power and channel control in the field of global food security. Furthermore we should explore the existing overseas agricultural investment market, reduce the geopolitical competition pressure and fully tap into potential market opportunities, focus on the agricultural technology demands of the BRI countries and region, and ensure that investment objectives are consistent with the investment demands of the host country. More importantly, it is necessary to solve practical problems faced with China's overseas investment in agriculture such as large cultural and institutional differences, which will improve the sustainability of agricultural cooperation projects under the BRI.
\end{abstract}

Keywords: overseas investment in agriculture; global agricultural resources; locational choice; the Belt and Road Initiative; USA 